\title{
Species richness, phylogenetic diversity and phylogenetic structure patterns of exotic and native plants along an elevational gradient in the Himalaya
}

Kumar Manish

\begin{abstract}
Background: So far, macroecological studies in the Himalaya have mostly concentrated on spatial variation of overall species richness along the elevational gradient. Very few studies have attempted to document the difference in elevational richness patterns of native and exotic species. In this study, this knowledge gap is addressed by integrating data on phylogeny and elevational distribution of species to identify the variation in species richness, phylogenetic diversity and phylogenetic structure of exotic and native plant species along an elevational gradient in the Himalaya.

Results: Species distribution patterns for exotic and native species differed; exotics tended to show maximum species richness at low elevations while natives tended to predominate at mid-elevations. Native species assemblages showed higher phylogenetic diversity than the exotic species assemblages over the entire elevational gradient in the Himalaya. In terms of phylogenetic structure, exotic species assemblages showed majorly phylogenetic clustering while native species assemblages were characterized by phylogenetic overdispersion over the entire gradient.

Conclusions: The findings of this study indicate that areas with high native species richness and phylogenetic diversity are less receptive to exotic species and vice versa in the Himalaya. Species assemblages with high native phylogenetic overdispersion are less receptive to exotic species than the phylogenetically clustered assemblages. Different ecological processes (ecological filtering in case of exotics and resource and niche competition in case of natives) may govern the distribution of exotic and native species along the elevational gradient in the Himalaya.
\end{abstract}

Keywords: Exotic species, Native species, Himalaya, Elevational gradient, Richness pattern

\section{Introduction}

Exotic species (non-native species introduced by human activity to the areas outside their natural distribution) cause both ecological and economic harms by lowering biological diversity, resource availability, human health and altering ecosystem functions (Sala et al. 2000; Pimentel et al. 2005; Vilà and Hulme 2017). Consequently, their management and control becomes highly important.

*Correspondence: kumarmanish910@gmail.com

Department of Environmental Studies, Dr. Bhim Rao Ambedkar College,

University of Delhi, Delhi, India
Generally, there are multiple and largely interactive factors that underlies the distribution of exotic species (Catford et al. 2009; Tarasi and Peet 2017) and it is equivocally debated as to what factors promote or reduce the spread of exotic species (Ibáñez et al. 2009; Gantchoff et al. 2018). In recent times, ecologists have increasingly used evolutionary relationships and phylogenetic metrics to analyze and investigate how exotic species are assembled and structured in new regions outside their areas of natural distribution (Cadotte et al. 2009, 2010; Lososová et al. 2015). 
Mountains occupy a total of 13.8 million $\mathrm{km}^{2}$ and $12.5 \%$ of the Earth's land surface (excluding Antarctica) and harbor one-quarter of total terrestrial species (Körner et al. 2016; Hoorn et al. 2018). Mountains not only act as harbingers of biodiversity and cradles of evolution, but they also provide numerous ecosystem services (Kier et al. 2009; Hoorn et al. 2018). In recent times, however, the spread of exotic species is threatening the quality and quantity of the ecosystem services accrued from mountain ecosystems (Pauchard et al. 2009; McDougall et al. 2011). In the lake cluster of Pokhara Valley of middle mountain Nepal, for example, yearly economic losses worth 0.19 million USD have been reported due to ecological invasion or spread of exotic species (Pathak et al. 2021). The mountain ecosystems that were earlier thought to be immune to the ecological invasion process (Averett et al. 2016) are now being increasingly invaded by exotic species due to climate and land-use changes, human population growth, road development, agricultural intensification and other anthropogenic activities (Dietz et al. 2006; Pauchard et al. 2009). There are increasing reports of colonization by non-native exotic species in the mountain areas around the world (Seipel et al. 2012; Morueta-Holme et al. 2015; Tecco et al. 2016).

The Himalayan ecosystems are increasingly experiencing more threats than any other mountain ecosystems of the world (Pandit 2017). The region has witnessed escalating anthropogenic pressures in recent decades, including extensive hydropower and infrastructure development coupled with urbanization, road construction, incessant tourism, deforestation and hunting (Pandit et al. 2014). Moreover, global warming and related climate changes have emerged as serious challenges to the Himalayan biodiversity (Telwala et al. 2013; Manish and Pandit 2019). Some estimates suggest that the region is warming at a rate three times faster than that of the global average (Shrestha et al. 2012; Pandit et al. 2014). Given the fact that the rich biodiversity of the Himalaya is critical for local livelihoods (Pandit et al. 2014; Pandit 2017) and spread of exotic species detrimentally affects the biodiversity (Pimentel et al. 2005), analyzing elevational distribution of exotic species in the Himalaya is very much needed (Khuroo et al. 2011; Ahmad et al. 2018). Most existing studies on the elevational species richness patterns in the Himalaya have focussed on documenting richness patterns for either native or endemic plant species (Vetaas and Grytnes 2002; Bhattarai and Vetaas 2003; Manish et al. 2017; Manish and Pandit 2018). Studies on exotic species richness patterns in the Himalaya have been generally been limited to preparing a checklist (Khuroo et al. 2007; Sekar 2012; Jaryan et al. 2013). Only a few studies have examined how patterns of native and exotic species differ in the Himalaya and even these have yielded contrasting results (see Kosaka et al. 2010; Khuroo et al. 2011; Bhattarai et al. 2014). This study attempts to address this knowledge gap by examining the elevational trends in species richness and phylogenetic diversity and phylogenetic structure of native and exotic species along a large elevational gradient $(300-5500 \mathrm{~m})$ in the Sikkim Himalaya by using a combination of traditional taxonomic metric (species richness), phylogenetic metric of diversity (phylogenetic diversity), and indices of phylogenetic structure (nearest taxon index and net relatedness index).

\section{Materials and methods Study area}

The present study was conducted in Sikkim, a constituent state of India and a part of the Eastern Himalayan global biodiversity hotspot (Fig. 1). The study area is situated between $27^{\circ} 00^{\prime} 46^{\prime \prime} \mathrm{N}$ and $28^{\circ} 07^{\prime} 48^{\prime \prime} \mathrm{N}$ latitude and $88^{\circ} 00^{\prime} 58^{\prime \prime} \mathrm{E}$ and $88^{\circ} 55^{\prime} 25^{\prime \prime} \mathrm{E}$ longitude and possesses a completely mountainous terrain with a natural elevational gradient ranging from 246 to $7873 \mathrm{~m}$ (Fig. 1). The total geographical area of the state is $7096 \mathrm{~km}^{2}$ and constitutes just $0.22 \%$ of India's total geographical area. More than 59\% of Sikkim's geographic area lies above $3000 \mathrm{~m}$, with slopes above $30 \%$ and $70 \%$ constituting more than $52 \%$ and $10 \%$ of the land area, respectively (CISMHE 2007). Sikkim receives a mean annual rainfall of about $2534 \mathrm{~mm}$, with monthly maximum rainfall of $480 \mathrm{~mm}$ in July and minimum rainfall of $19 \mathrm{~mm}$ in December. The mean annual temperature of Sikkim is $18{ }^{\circ} \mathrm{C}$, with minimum temperature of $-13{ }^{\circ} \mathrm{C}$ in alpine zones and maximum temperature of $26{ }^{\circ} \mathrm{C}$ at low and mid-elevations (CISMHE 2007). In recent years, there have been reports of fast colonization and encroachment of exotic plant species in farmlands, pristine forests and grasslands, leading to productivity declines and economic losses (Sharma and Rai 2012; Pandit 2017).

\section{Species data}

Data on species occurrence, nomenclature, family and their respective elevational distribution and elevational range were collected from previously published records, databases, checklists and online resources (see Additional file 1: Appendix S1). The recorded plant species were categorized into exotic species and native species; exotic species included any non-native species, i.e., naturalized, casual, invasive and cultivated species that occur outside their center of origin and natural adapted ranges (see Jaryan et al. 2013; Pyšek et al. 2004; Raghubanshi et al. 2005), while native species included the native Himalayan species that are found in the Sikkim Himalayan region (see Additional file 1: Appendix S1). To determine the nativity of species, a host of published and online 


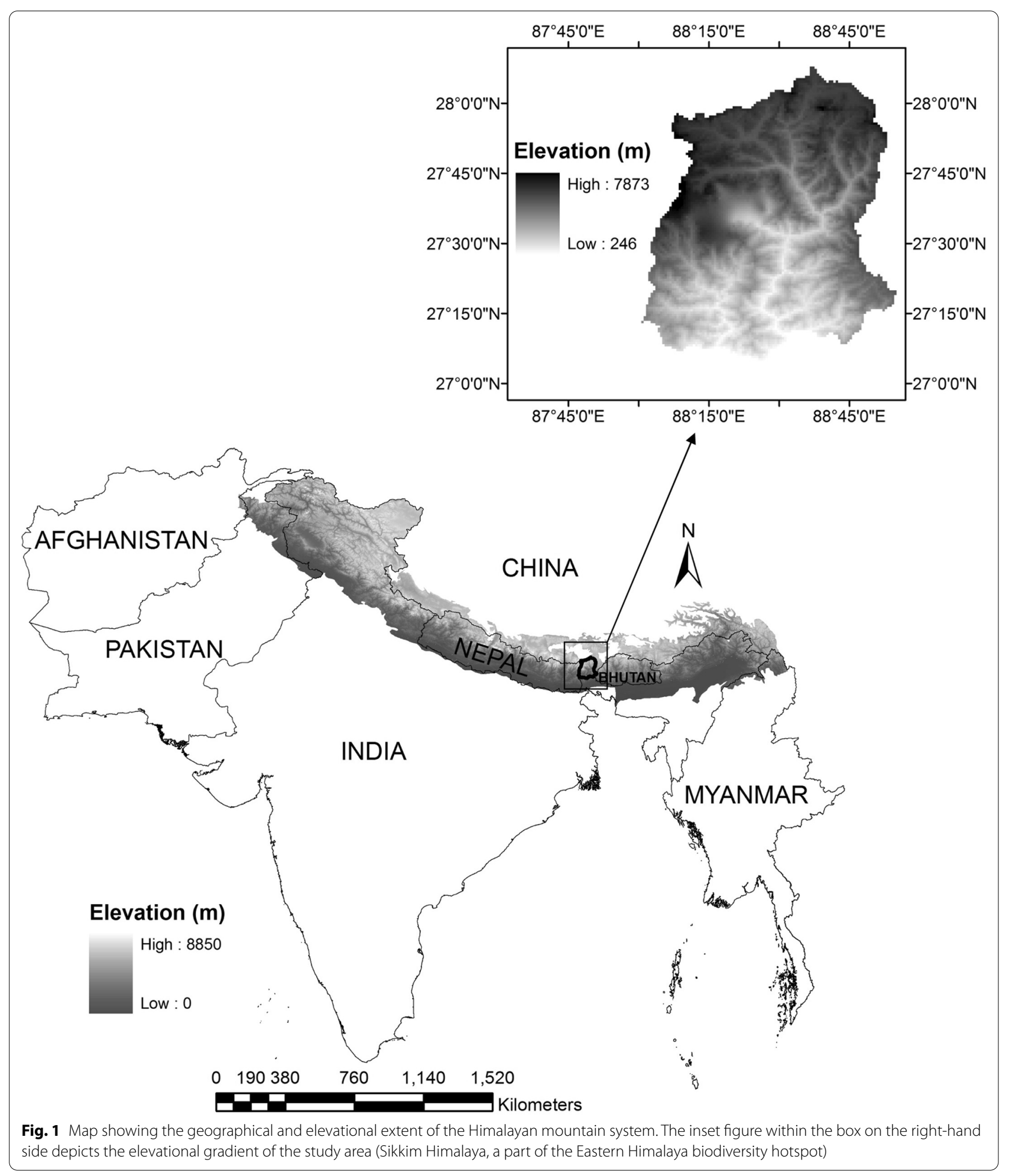

sources including efloras (http://www.efloras.org/), Flora Himalaya database (www.leca.univ-savoie.fr/db/ florhy/infos.html), Plants of the World database (http:// www.plantsoftheworldonline.org/), Flora of British India
(Hooker 1875-1897), Flora of Sikkim (Hajra and Verma 1996; Srivastava 1998) and other published records, literature and checklists were used (see Additional file 1: Appendix S1). 


\section{Species richness patterns}

The elevational gradient of Sikkim Himalaya between 300 and $5500 \mathrm{~m}$ was divided into $100 \mathrm{~m}$ equal elevational bands. The lowermost elevational limit $(300 \mathrm{~m})$ represents the southernmost point of the study region (Melli Bazar, $246 \mathrm{~m}$ rounded to the nearest upper $100 \mathrm{~m}$ elevation), while the highest elevational limit $(5500 \mathrm{~m})$ marks the limit beyond which no species were recorded. Thus, there were a total of 53 elevational bands $(100 \mathrm{~m}$ each) for both exotic and native species. Interpolation method was used to estimate the number of species or species richness in each elevational band. A species was assumed to be present in each elevational band between its recorded lowermost and uppermost elevational limits and no species was assumed to have an elevational distribution range of less than $100 \mathrm{~m}$ (see Grytnes and Vetaas 2002; Manish et al. 2017). Interpolation method has been reported to be the most accurate estimator of species richness among all parametric and non-parametric estimators in the Himalayan region (see Manish et al. 2017). A species recorded at a single site was given an elevational range of $100 \mathrm{~m}$ and included in the analyses in accordance with the standard literature (see Bhattarai and Vetaas 2006; Manish et al. 2017). Friedman's super smoother function in TIBCO Spotfire $S+8.1$ software was used to decipher the species richness patterns along the elevational gradient and analyze the relationship between species richness and elevation for both exotic and native species. Friedman's super smoother function creates a smooth curve around the data points by automatically determining the level of smoothness using cross-validation technique (Friedman and Silverman 1989). In this way, the Friedman's super smoother function has an advantage over the normal regression techniques like generalized linear models (GLM) and generalized additive models (GAM) that are commonly used to document species richness patterns (see Vetaas and Grytnes 2002; Bhattarai and Vetaas 2006; Bhatt et al. 2012; Manish et al. 2017) as the curve generated by the super smoother function is dictated by the data contained in the dataset itself while curves generated by GLM and GAM are generally limited by the statistical parameters and distribution of the models (Pedersen et al. 2019).

\section{Phylogenetic analyses}

A megatree approach was used to construct family-level phylogenetic trees for exotic and native plant species using the Phylomatic tool of Phylocom ver. 4.2 (Webb et al. 2008) and the modified protocol of Webb et al. (2008) and Manish and Pandit (2018). Such a megatree approach has been successfully used in a number of previous studies for estimating the phylogenetic diversity and structure in different regions where molecular data for species do not exist (Li et al 2014; Qian et al. 2016; Manish et al. 2021). For preparing the family-level phylogenetic trees, the data on the exotic and native species occurrences in different elevational bands of the study area and a backbone family-level Angiosperm Phylogeny Group IV seed plant supertree (R20160415.new) of Gastauer et al. (2017) in the Phylocom software were used. The Phylomatic tool in Phylocom software generated uncalibrated family-level phylogenetic trees for exotic and native species with equal branch lengths. The branch lengths in these uncalibrated trees were calibrated using the Branch Length Adjustment algorithm (BLADJ) tool (Webb 2000) in Phylocom based on the angiosperm nodes contained in the dated tree of Bell et al. (2010). The BLADJ calibrated family-level phylogenetic trees of exotic and native species were then used as a base for determining phylogenetic diversity and phylogenetic structure patterns of exotic and native species along the elevational gradient in the study area.

\section{Phylogenetic diversity patterns}

Several ways to quantify phylogenetic diversity (PD) exist in literature (see Kellar et al. 2015). Of these, some are based on abundance measures (Hill numbers, Chao et al. 2010), incidence data (Faith's PD, Faith 1992), or entropy calculations (Rao's quadratic entropy, Rao 1982). In this study, I used Faith's PD measure to quantify PD of each elevational band as it can be used with species occurrence data (Faith 1992; Morlon et al. 2011). Faith's PD can be defined as the minimum total length of all the existing phylogenetic branches required to span across all taxa in a given phylogenetic tree (Faith 1992; Faith and Baker 2006).

PD values of exotic and native species were calculated for each $100 \mathrm{~m}$ elevational band using the respective BLADJ calibrated family-level phylogenetic trees in $\mathrm{R}$ 2.14.0 software (R Development Core Team 2011) utilizing the "picante" package (Kembel et al. 2010). Friedman's super smoother function in TIBCO Spotfire $S+8.1$ software was used to explore the relationship between PD and elevation in the study area. Pearson's correlation coefficient was used to analyze the significance and strength of association between PD and species richness of exotic and native species along the elevational gradient of the study area.

\section{Phylogenetic structure}

Phylogenetic structure indicates the phylogenetic distribution of taxa in a community or species assemblages (Manish and Pandit 2018). Net relatedness index (NRI) and nearest taxon index (NTI) are used as indices of phylogenetic structure to analyze the variation of phylogenetic structure of exotic and native plant species 
assemblages along the Sikkim Himalayan elevational gradient. Both the indices have been quite frequently used in literature to document the phylogenetic structure of plant communities ( $\mathrm{Li}$ et al. 2014; Manish and Pandit 2018). NRI is used to analyze phylogenetic relatedness among different species in a species assemblage by measuring the mean phylogenetic distance between taxa in a phylogenetic tree, while NTI is used to analyze phylogenetic relatedness by calculating mean nearest taxon distance between terminal taxa in a phylogenetic tree (Kamilar et al. 2015; Manish and Pandit 2018). The following modified formulae of Webb (2000) and Webb et al. (2008) were used to calculate the values of NRI and NTI in each $100 \mathrm{~m}$ elevational band for exotic and native species in R 2.14.0 using the "picante" package (Kembel et al. 2010):

$$
\begin{aligned}
& \mathrm{NRI}=-1 \times\left(\frac{\mathrm{MPD}_{\mathrm{o}}-\mathrm{MPD}_{\mathrm{r}}}{\mathrm{sdMPDr}}\right), \\
& \mathrm{NTI}=-1 \times\left(\frac{\mathrm{MNTD}_{\mathrm{o}}-\mathrm{MNTDr}}{\mathrm{sdMNTDr}}\right),
\end{aligned}
$$

where NRI $=$ net relatedness index, $\mathrm{MPD}_{\mathrm{o}}=$ observed mean phylogenetic distance in the phylogenetic tree, $M P D_{r}=$ expected mean phylogenetic distance of species assemblages that were randomized, $\operatorname{sdMPD}_{\mathrm{r}}=$ standard deviation of mean phylogenetic distance of species assemblages that were randomized, NTI $=$ nearest taxon index, $\mathrm{MNTD}_{\mathrm{o}}=$ observed mean nearest taxon distance in the phylogenetic tree, $\mathrm{MNTD}_{\mathrm{r}}=$ expected mean nearest taxon distance of species assemblages that were randomized, $\operatorname{sdMNTD}_{\mathrm{r}}=$ standard deviation of mean nearest taxon distance of species assemblages that were randomized. Randomized species assemblages were created using a null model that shuffled the phylogeny tip labels across all taxa included in a phylogenetic tree using the R package "picante" (Kembel et al. 2010). The statistical significance of the NRI and NTI values in each elevational band was assessed against this null model with a total of 999 iterations (see Manish and Pandit 2018).

The positive values of NRI and NTI $(>0)$ in the current study indicated presence of phylogenetic clustering (i.e., more species belonged to closely related evolutionary families than that expected by chance), while negative values of NRI and NTI $(<0)$ indicated phylogenetic overdispersion (i.e., more species belonged to distantly related evolutionary families than that expected by chance). The variation of NRI and NTI along the elevational gradient of the study area was analyzed with the help of Friedman's super smoother function in TIBCO Spotfire $S+8.1$ software.

\section{Results}

A total of 307 exotic angiosperm species belonging to 55 families and 1274 native angiosperm species belonging to 100 families were recorded in the Sikkim Himalayan region (see Additional file 1: Tables S1, S2). The families with most exotic species in the decreasing order were Poaceae (53 species), Asteraceae (49 species), Fabaceae (29 species), Cyperaceae (26 species) and Amaranthaceae (14 species). These 5 dominant families contributed to about $56 \%$ of the exotic flora in the study area (see Additional file 1: Table S1). On the other hand, the families with most native species in decreasing order were Orchidaceae (222 species), Asteraceae (77 species), Primulaceae (55 species), Poaceae (48 species) and Ericaceae (41 species) contributing to a total of approximately $35 \%$ of the native flora of the study area (see Additional file 1: Table S2). The average elevational range of the exotic species along the entire elevational gradient was slightly higher $(1074 \pm 632 \mathrm{~m})$ than that of the native species $(1002 \pm 630 \mathrm{~m})$.

Species richness and phylogenetic diversity patterns revealed unimodal hump-shaped curves along the elevational gradient for both exotic and native species in the study area (Fig. 2). However, the peaks of species richness and phylogenetic diversity varied for exotic and native species (Figs. 2 and 3). Maximum exotic species richness was observed at low elevations in the 700-1000 m elevation bands, while native species showed a species richness peak at high elevations in the $3300-3700 \mathrm{~m}$ elevational bands (Fig. 2A). Similarly, the peak of phlyogenetic diversity was observed in the $500-1000 \mathrm{~m}$ elevational bands for exotic species and 2800-3500 m elevational bands for native species (Fig. 2B). A strong and significant positive Pearson's correlation coefficient was found between species richness and phylogenetic diversity for both exotic species $(r=0.98, P<0.001)$ and native species $(r=0.96$, $P<0.001$ ) along the elevational gradient (Fig. 4 ), suggesting that the patterns of species richness and phylogenetic diversity along the elevational gradient almost mirror each other for exotic and native species in the study area.

The results of phylogenetic structure analyses revealed that exotic species showed phylogenetic clustering (NRI and NTI values $>0$ ) between 300-1400 m, 1900-2500 m, $4100-4500 \mathrm{~m}$ and phylogenetic overdispersion (NRI and NTI values $<0$ ) between $1500-1800 \mathrm{~m}, 2600-4000 \mathrm{~m}$ and 4600-5500 m elevations (Fig. 5). On the other hand, native species showed phylogenetic overdispersion throughout the elevational gradient except between $1200-1500 \mathrm{~m}$ and $2500-3200 \mathrm{~m}$ elevations where phylogenetic clustering was observed (Fig. 5). This indicated that the exotic and native species exhibited different phylogenetic structures within the same study area and also revealed that the indices of phylogenetic structure (NRI 

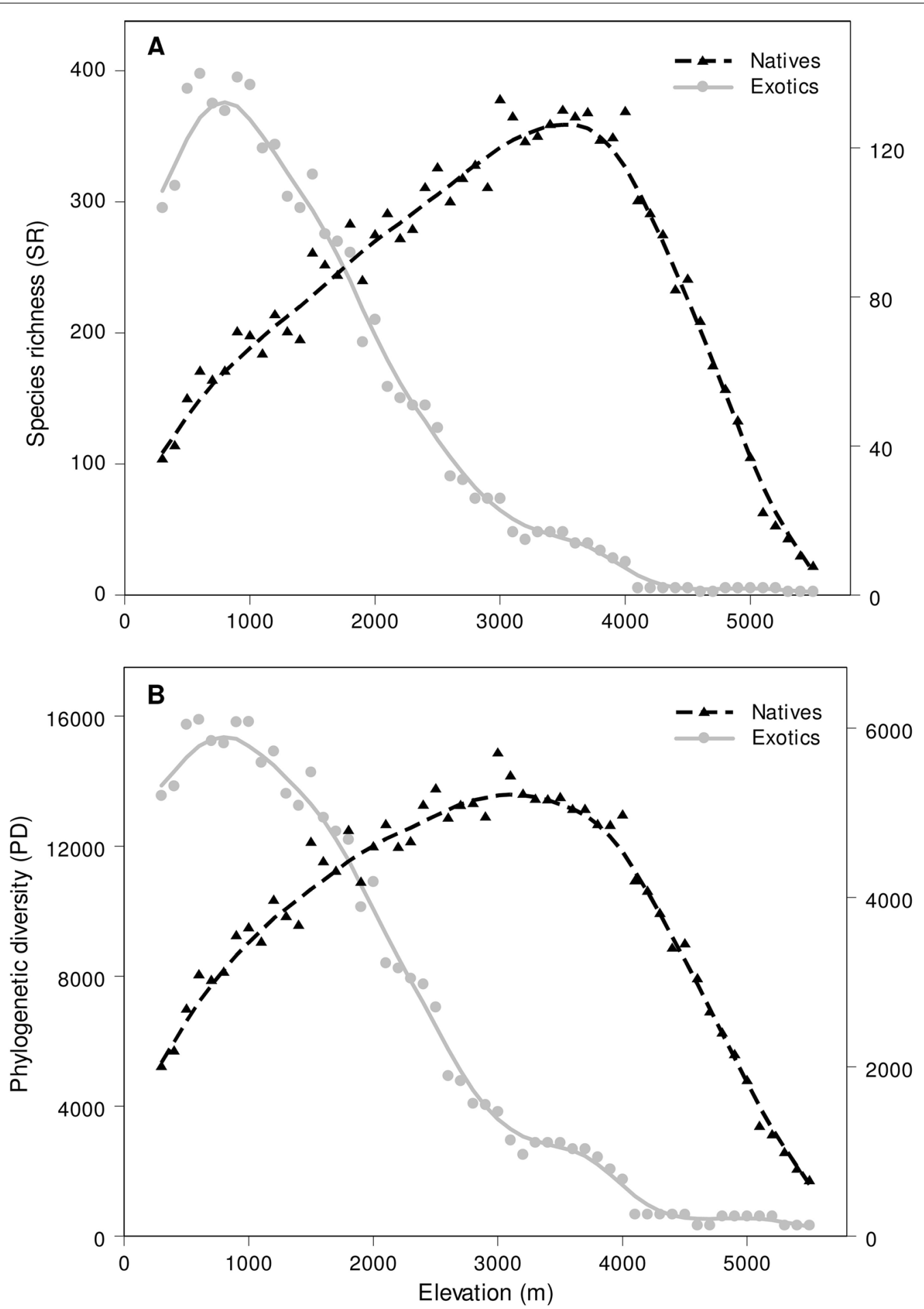

Fig. 2 Variation of (A) Species richness (SR) and (B) Phylogenetic diversity (PD) of exotic and native plant species along the elevational gradient in Sikkim Himalaya. Both exotic and native plant species showed unimodal hump-shaped curves for PD and SR along the elevational gradient. The primary $Y$-axis in both the plots represents SR and PD of native species, while secondary $Y$-axis represents SR and PD of exotic species. The fitted lines in both the plots were generated using Friedman's super smoother function and do not imply any cause-effect relationship 


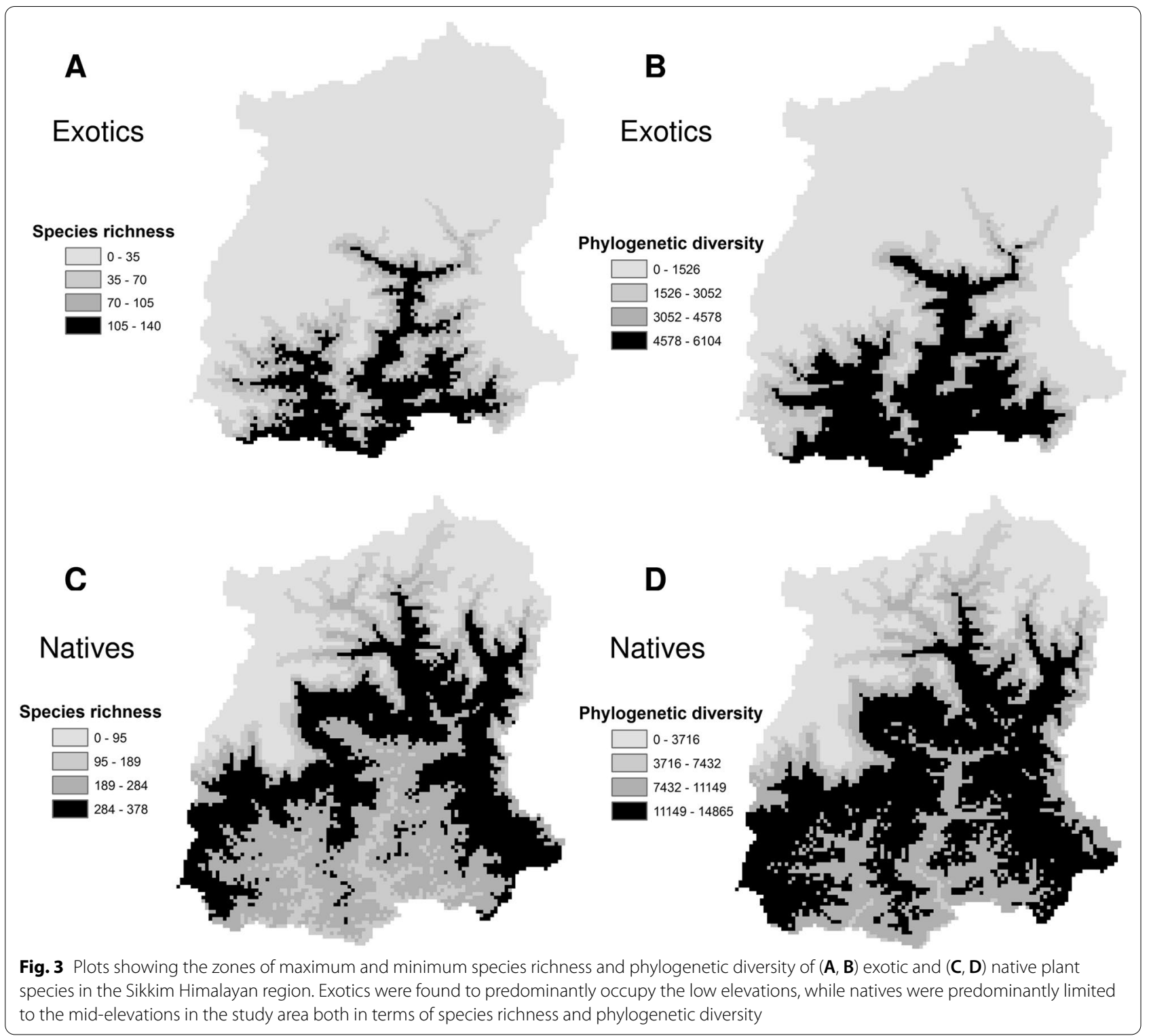

and NTI) did not differ much for both exotic and native taxa (Fig. 5). Thus, the choice of the metric of phylogenetic structure did not influence the overall results in the current study.

\section{Discussion}

The results of the present study indicate that the exotic and native plant species show different species distribution and phylogenetic diversity patterns along the Sikkim Himalayan elevational gradient, albeit both of them showed hump-shaped pattern. Hump-shaped species distribution patterns have been reported to be the most generalized and common pattern of species distribution along the elevational gradient in the Himalaya (see Vetaas and Grytnes 2002; Grytnes and Vetaas 2002; Carpenter 2005; Bhatt et al. 2012; Manish et al. 2017; Manish 2019). The hump-shaped patterns in species distributions may be correlated to a combination of different ecological factors such as climatic constraints, dispersal limitations or environmental filters that governs the distribution of various taxa in the study area. For example, ambient energy and water availability have been reported to govern the overall distribution of plant species richness patterns and both these factors also show hump-shaped patterns when plotted along the elevational gradient in the Sikkim Himalaya region (Manish et al. 2017). Similarly, productivity and environmental heterogeneity have a unimodal relationship with species richness that may 


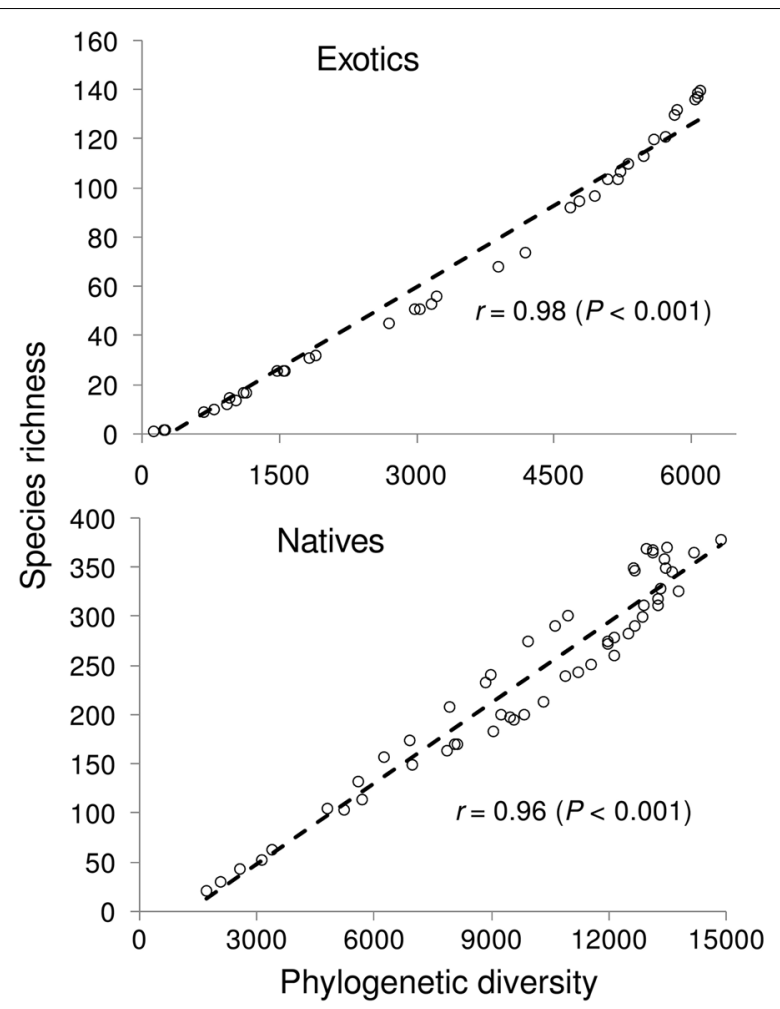

Fig. 4 Relationship between species richness and phylogenetic diversity of exotic and native species along the elevational gradient in the Sikkim Himalayan region. Significant positive correlations were observed between species richness and phylogenetic diversity for both exotic and native species along the elevational gradient

result in hump-shaped patterns (Stein et al. 2014; Fraser et al. 2015).

Exotic plant species showed maximum species richness and phylogenetic diversity at low elevations (700$1000 \mathrm{~m}$ and 500-1000 m, respectively), while maximum native plant species and native phylogenetic diversity were recorded at high elevations $(3300-3700 \mathrm{~m}$ and 2800-3500 m, respectively). Similar results have been reported earlier in the Himalaya by Kosaka et al. (2010), Ahmad et al. (2018) and Dar et al. (2018). Kosaka et al. (2010) found maximum exotic species richness in the low-elevation tropical forests $(100-1600 \mathrm{~m})$ in the neighboring state of Arunachal Pradesh (a part of the same Eastern Himalayan biogeographic region as that of Sikkim). Ahmad et al. (2018) found maximum exotic species richness in 1000-1100 m elevational bands in Himachal Pradesh (Western Himalaya), while Dar et al. (2018) reported a general decline in exotic plant species richness with increasing elevation in the Kashmir Himalayan region (Western Himalaya). More exotic species richness is expected at low elevations in the mountains because of favorable climates, low geographic and climate isolation, high human disturbance, high road and human population densities, less environmental heterogeneity and less extreme habitats (Becker et al. 2005; Pauchard et al. 2009). Low temperature, low ecosystem productivity, short growing season and low precipitation at high elevations limit spread of exotic species in the Himalaya (Manish et al. 2017). In a way, the present results conform to the "directional ecological filtering" hypothesis proposed by Alexander et al. (2011) that posits uniform decline of exotic species along the elevational gradient in the mountain areas as exotic species cannot successfully establish under the extreme environmental conditions that keep on increasing with elevation. Due to greater stress at high elevations, only exotic species with narrow climatic ranges and specialists with adaptation to the extreme ecophysiological conditions such as low temperature, slow growth rate, etc., are able to survive (Alexander et al. 2011; Marini et al. 2013). Another reason that can be attributed to the decline of exotic species richness at high elevations is the lack of pre-adaptation of exotic species to survive in extreme conditions at high elevations and lack of colonization of high elevation areas (Alexander et al. 2016). Native species on the other hand showed maximum preponderance and phylogenetic diversity at the mid-elevations. The mid-elevations of the study area have been previously reported to be the regions of highest endemic plant species richness and endemic phylogenetic diversity (Manish and Pandit 2018). This is likely due to multiple evolutionary diversifications and adaptive radiations linked to habitat isolation and vicariance driven by isolated mountain peaks and highly dissected river valleys at the mid-elevations in the Sikkim Himalaya (see Pandit 2017; Manish and Pandit 2018). The mid-elevations of Sikkim Himalaya are also the harbingers of most ancestral/primitive plant species in the region and are the areas where speciation, diversification and accumulation events have been occurring for the longest periods of time in the region (Manish and Pandit 2018). Thus, the occurrence of native plant species richness and phylogenetic diversity maxima at higher elevations than the exotic species in the present study seems to be justified. By contrary, Bhattarai et al. (2014) reported that both exotic and native species richness peaked in the same elevational range (600-1100 m) in the Nepal Himalaya. A probable reason for this can be that Bhattarai et al. (2014) included just one lifeform (trees) for comparison of distribution patterns of exotic and native species in their study. Trees irrespective of whether they are endemic, native or exotic generally tend to dominate at low elevations in the Himalaya due to the ecophysiological and climatic limitations (Manish et al. 2017). The present study is more comprehensive than Bhattarai et al. (2014) as it includes all lifeforms (trees, shrubs, climbers and herbs) and presents 

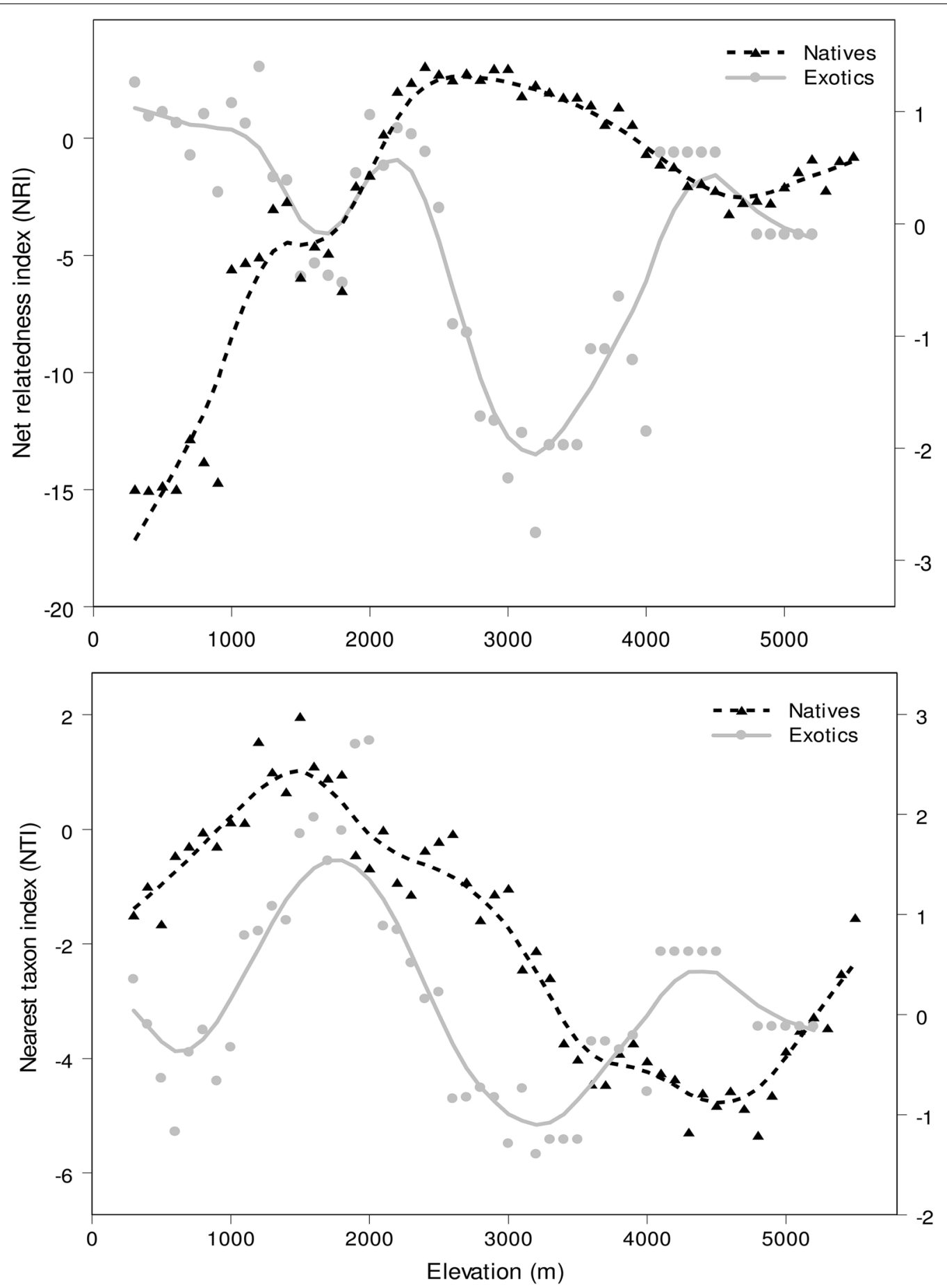

Fig. 5 Plots showing the variation of phylogenetic structure of exotic and native plant species along the Sikkim Himalayan elevational gradient Phylogenetic structure was measured using net relatedness index (NRI) and nearest taxon index (NTI). Overall, exotics showed phylogenetic clustering (NRI and NTI>0) and natives showed phylogenetic overdispersion (NRI and NTI<0) along the elevational gradient. In both the plots, the primary $Y$-axis represents NRI and NTI values of native species, while secondary Y-axis represents NRI and NTI values of exotic species. The fitted lines in both the plots were generated using Friedman's super smoother function and do not imply any cause-effect relationship 
a more generalized pattern. Elsewhere, species richness and diversity patterns can vary with life-forms and geographic status (native and endemic) in the Himalaya (see Manish et al. 2017; Manish 2019). Therefore, it is more meaningful to analyze the diversity and distribution patterns only after including the entire life-form spectrum of the taxa under investigation. An important finding of the present study is that the areas with low native species richness and phylogenetic diversity (low elevations in the current study) offer greater ecological opportunities for the establishment of exotic species. This study therefore tends to agree with the hypothesis that 'low native species diversity promotes exotic species diversity' (Elton 1958; Naeem et al. 2000; Dark 2004) as opposed to the 'high native species diversity promotes exotic species diversity' hypothesis (Stohlgren et al. 1999; Levine 2000; Gilbert and Lechowiez 2005). High native species richness leads to decreased exotic receptivity mainly because of increased resource competition, high functional diversity and lack of empty niches (Elton 1958; Kennedy et al. 2002; Sol et al. 2012).

The results of phylogenetic structure analyses in the present study revealed that exotic species generally showed phylogenetic clustering and native species showed phylogenetic overdispersion in the areas with respective maximum species richness and phylogenetic diversity (Fig. 5). These findings are similar to that of Cadotte et al. (2010) and Carvallo et al. (2014) who reported low phylogenetic diversity and phylogenetic clustering in the exotic clades and phylogenetic overdispersion in the native communities. Various authors have pointed out that the presence of phylogenetic clustering indicates 'ecological filtering' while phylogenetic overdispersion indicates 'competition' (Webb et al. 2002; Li et al. 2014; Manish and Pandit 2018). It is likely that 'directional ecological filtering' (Alexander et al. 2011) shapes the phylogenetic structure and overall species composition of exotic species in Sikkim Himalaya by only selecting lineages with ability to tolerate anthropogenic disturbances, high stress and fluctuating resources at low elevations and minimum temperature at high elevations. The overrepresentation of a few families such as Poaceae, Asteraceae, Fabaceae, Cyperaceae and Amaranthaceae that together make up $56 \%$ of the exotic flora is also likely to dictate the phylogenetic clustering of exotic species with majority of the species belonging to these families being annuals with rapid growth and having the ability of producing copious seeds with good dispersal ability (Additional file 1: Table S1). The results also reveal that less number of exotic species is found in those areas where there is high phylogenetic overdispersion of native species assemblages (Fig. 5). Phylogenetic overdispersion is the result of strong competition between closely related species due to the dependence on the same resources as a result of their shared ancestry (Webb et al. 2002; Lososová et al. 2015). Thus, the intense resource competition and lack of empty niches drive out the exotic species in areas with high native phylogenetic diversity and overdispersion.

It is amply clear from the present study that the exotic species are currently limited to the low-elevation tropical regions in the Himalaya. This is however likely to change in near future with climate change and increased human disturbance including urbanization, road development, agricultural intensification, tourism, etc. With global warming, the low temperature constraint on exotic species might be reduced and lead to the spread of exotic species towards high elevations. Unplanned road development can cause recurring disturbances including changing species composition, local hydrology, soil ecology, microclimate, and fragmenting habitats (Forman et al. 2003; Müllerová et al., 2011). These changes can both serve as important sources of propagules and facilitate the establishment of exotic species (Johnston and Pickering 2001; Godfree et al. 2004). In many studies, it has been shown that exotic species first colonize the low elevations and then spread upwards with increasing disturbances and anthropogenic pressures with time (Guo et al. 2018; Yang et al. 2018). This poses a serious threat to the alpine ecosystems of the Himalaya that are important harbingers of endemic biodiversity and medicinal plants and are important sources of local livelihoods (see Pandit 2017). The conservation managers and policy-makers would have to carefully and pragmatically manage development including road and infrastructure development, urbanization and tourism in areas with high native biodiversity and perhaps it would be better to leave these areas as undisturbed and excluded from any kind of anthropogenic disturbance.

\section{Conclusions}

This study presents five broad ideas: (i) species distribution patterns for exotic and native plant species differ in the Himalaya; exotics tend to show maximum species richness at low elevations while natives tend to predominate at mid-elevations; (ii) native plant species assemblages show higher phylogenetic diversity than the exotic species assemblages over the entire elevational gradient in the Himalaya; (iii) exotic plant species assemblages show majorly phylogenetic clustering while native species assemblages are characterized by phylogenetic overdispersion over the entire Himalayan elevational gradient; (iv) areas with high native species richness and phylogenetic diversity are less receptive to exotic species and vice versa in the Himalaya; (v) the assembly of exotic plant species in the Himalaya is shaped by ecological 
filtering while native species assemblages are dictated by resource and niche competitions. Future studies in the region should be directed towards examining the critical functional traits that influence community assembly and species assemblage patterns of the natives and exotics, and how niche partitioning occurs in the invaded and un-invaded habitats. It is also necessary to do long-term monitoring of the changes in the distribution of exotic species along the elevational gradient and determine the temporal shift in their distribution patterns in order to assess the effect of climate change in the region. Climate change in particular is expected to favor the expansion of low-elevation exotic plant species into the temperate and alpine habitats. This can greatly threaten the existence of endemic species that predominate in these habitats due to their low tolerance to changing environmental conditions and encroaching exotic species. Studies along these lines would help the conservation managers and policymakers to effectively limit the spread of exotic species in the Himalaya.

\section{Supplementary Information}

The online version contains supplementary material available at https://doi. org/10.1186/s13717-021-00335-z.

Additional file 1: Appendix S1. List of published records used for collating data on exotic and native species occurrences, nomenclatures, families and their respective elevational distribution and elevational ranges in Sikkim Himalaya. Table S1. List of exotic angiosperm species of the Sikkim Himalayan region. The species have been listed alphabetically according to their names. Table S2. List of native angiosperm species of the Sikkim Himalayan region. The species have been listed alphabetically according to their names.

\section{Acknowledgements}

The author acknowledges the support of Dr. Bhim Rao Ambedkar College, University of Delhi, during the course of this study.

\section{Authors' contributions}

KM conceptualized the study, collected and analyzed the data and wrote the manuscript. The author read and approved the final manuscript.

\section{Funding}

The study is self-financed.

\section{Availability of data and materials}

The raw data for this manuscript (species list) are included in the Additional Material.

\section{Declarations}

\section{Ethics approval and consent to participate}

No formal approval is required for this study since this article does not contain any studies with human participants, animals or on-site data collection.

\section{Consent for publication}

Not applicable.

\section{Competing interests}

The author declares that he has no competing interests.
Received: 27 May 2021 Accepted: 26 September 2021

Published online: 09 October 2021

\section{References}

Ahmad M, Uniyal SK, Singh RD (2018) Patterns of alien plant species richness across gradients of altitude: analyses from the Himalayan state of Himachal Pradesh. Trop Ecol 59:35-43

Alexander JM, Kueffer C, Daehler CC, Edwards PJ, Pauchard A, Seipel T, Miren Consortium (2011) Assembly of nonnative floras along elevational gradients explained by directional ecological filtering. Proc Natl Acad Sci USA 108:656-661

Alexander JM, Lembrechts JJ, Cavieres LA, Daehler C, Haider S, Kueffer C, Liu G, McDougall K, Milbau A, Pauchard A, Rew L (2016) Plant invasions into mountains and alpine ecosystems: current status and future challenges. Alp Bot 126:89-103

Averett JP, McCune B, Parks CG, Naylor BJ, DelCurto T, Mata-Gonzalez R (2016) Non-native plant invasion along elevation and canopy closure gradients in a middle Rocky Mountain ecosystem. PLoS ONE 11:e0147826. https:// doi.org/10.1371/journal.pone.0147826

Becker T, Dietz H, Billeter R, Buschmann H, Edwards PJ (2005) Altitudinal distribution of alien plant species in the Swiss Alps. Perspect Plant Ecol Evol Syst 7:173-183

Bell CD, Soltis DE, Soltis OS (2010) The age and diversification of the angiosperms re-revisited. Am J Bot 97:1296-1303

Bhatt JP, Manish K, Pandit MK (2012) Elevational gradients in fish diversity in the Himalaya: water discharge is the key driver of distribution patterns. PLoS ONE 7:e46237. https://doi.org/10.1371/journal.pone.0046237

Bhattarai KR, Vetaas OR (2003) Variation in plant species richness of different life forms along a subtropical elevation gradient in the Himalayas, east Nepal. Glob Ecol Biogeogr 12:327-340

Bhattarai KR, Vetaas OR (2006) Can Rapoport's rule explain tree species richness along the Himalayan elevation gradient, Nepal? Divers Distrib 12:373-378

Bhattarai KR, Måren IE, Subedi SC (2014) Biodiversity and invasibility: distribution patterns of invasive plant species in the Himalayas, Nepal. J Mt Sci 11:688-696

Cadotte MW, Hamilton MA, Murray BR (2009) Phylogenetic relatedness and plant invader success across two spatial scales. Divers Distrib 15:481-488

Cadotte MW, Borer ET, Seabloom EW, Cavender-Bares J, Harpole WS, Cleland E, Davies KF (2010) Phylogenetic patterns differ for native and exotic plant communities across a richness gradient in Northern California. Divers Distrib 16:892-901

Carpenter C (2005) The environmental control of plant species density on a Himalayan elevation gradient. J Biogeogr 32:999-1018

Carvallo GO, Teillier S, Castro SA, Figueroa JA (2014) Phylogenetic properties of exotic communities. Austral Ecol 39:304-312

Catford JA, Jansson R, Nilsson C (2009) Reducing redundancy in invasion ecology by integrating hypotheses into a single theoretical framework. Divers Distrib 15:22-40

Centre for Inter-disciplinary Studies of Mountain and Hill Environment, University of Delhi, Delhi (CISMHE) (2007) Carrying capacity study of Teesta basin in Sikkim. Executive Summary and Recommendations. Delhi: University of Delhi

Chao A, Chiu CH, Jost L (2010) Phylogenetic diversity measures based on Hill numbers. Philos Trans R Soc Lond B Biol Sci 365:3599-3609

Dar PA, Reshi ZA, Shah AB (2018) Altitudinal distribution of native and alien plant species along roadsides in Kashmir Himalaya, India. Trop Ecol 59:45-55

Dark SJ (2004) The biogeography of invasive alien plants in California: an application of GIS spatial regression analysis. Divers Distrib 10:1-9

Dietz H, Kueffer C, Parks CG (2006) MIREN: a new research network concerned with plant invasion into mountain areas. Mt Res Dev 26:80-81

Elton CS (1958) The ecology of invasions by animals and plants. Methuen, London

Faith DP (1992) Conservation evaluation and phylogenetic diversity. Biol Conserv 61:1-10

Faith DP, Baker AM (2006) Phylogenetic diversity (PD) and biodiversity conservation: some bioinformatics challenges. Evol Bioinform Online 2:121-128. https://doi.org/10.1177/117693430600200007 
Forman RTT, Sperling D, Bissonette JA, Clevenger AP, Cutshall CD, Dale VH, Fahrig L, France R, Goldman CR, Heanue K et al (2003) Road ecology: science and solutions. Island Press, Washington DC

Fraser LH, Pither J, Jentsch A, Sternberg M, Zobel M, Askarizadeh D, Bartha S, Beierkuhnlein C, Bennett JA, Bittel A, Boldgiv B (2015) Worldwide evidence of a unimodal relationship between productivity and plant species richness. Science 349:302-305

Friedman JH, Silverman BW (1989) Flexible parsimonious smoothing and additive modeling. Technometrics 31:3-21

Gantchoff MG, Wilton CM, Belant JL (2018) Factors influencing exotic species richness in Argentina's national parks. PeerJ 6:e5514. https://doi. org/10.7717/peerj.5514

Gastauer M, NetoM AJA (2017) Updated angiosperm family tree for analyzing phylogenetic diversity and community structure. Acta Bot Bras 31:191-198

Gilbert B, Lechowicz MJ (2005) Invasibility and abiotic gradients: the positive correlation between native and exotic plant diversity. Ecology 86:1848-1855

Godfree R, Lepschi B, Mallinson D (2004) Ecological filtering of exotic plants in an Australian sub-alpine environment. J Veg Sci 15:227-236

Grytnes JA, Vetaas OR (2002) Species richness and altitude: a comparison between null models and interpolated plant species richness along the Himalayan altitudinal gradient, Nepal. Am Nat 159:294-304

Guo Q, Fei S, Shen Z, lannone BV, KnottJ CSL (2018) A global analysis of elevational distribution of non-native versus native plants. J Biogeogr 45:793-803

Hajra PK, Verma DM (1996) Flora of Sikkim. Botanical Survey of India, Calcutta

Hooker JD (1875-1897) Flora of British India, Volume 1-7. London: Reeve and Co.

Hoorn C, Perrigo A, Antonelli A (2018) Mountains, climate and biodiversity. Wiley-Blackwell, Chichester

Ibáñez I, Silander JA Jr, Wilson AM, LaFleur N, Tanaka N, Tsuyama I (2009) Multivariate forecasts of potential distributions of invasive plant species. Ecol Appl 19:359-375

Jaryan V, Uniyal SK, Gupta RC, Singh RD (2013) Alien flora of Indian Himalayan State of Himachal Pradesh. Environ Monit Assess 185:6129-6153

Johnston FM, Pickering CM (2001) Alien plants in the Australian Alps. Mt Res Dev 21:284-291

Kamilar JM, Beaudrot L, Reed KE (2015) Climate and species richness predict the phylogenetic structure of African mammal communities. PLOS ONE 10:e0121808. https://doi.org/10.1371/journal.pone.0121808

Kellar PR, Ahrendsen DL, Aust SK, Jones AR, Pires JC (2015) Biodiversity comparison among phylogenetic diversity metrics and between three North American prairies. Appl Plant Sci 3:1400108. https://doi.org/10. 3732/apps. 1400108

Kembel SW, Cowan PD, Helmus MR, Cornwell WK, Morlon H, Ackerly DD, Blomberg SP, Webb CO (2010) Picante: R tools for integrating phylogenies and ecology. Bioinformatics 26:1463-1464

Kennedy TA, Naeem S, Howe KM, Knops JM, Tilman D, Reich P (2002) Biodiversity as a barrier to ecological invasion. Nature 417:636-638

Khuroo AA, Rashid I, Reshi Z, Dar GH, Wafai BA (2007) The alien flora of Kashmir Himalaya. Biol Invasions 9:269-292

Khuroo AA, Weber E, Malik AH, Reshi ZA, Dar GH (2011) Altitudinal distribution patterns of the native and alien woody flora in Kashmir Himalaya, India. Environ Res 111:967-977

Kier G, Kreft H, Lee TM, Jetz W, Ibisch PL, Nowicki C, Mutke J, Barthlott W (2009) A global assessment of endemism and species richness across island and mainland regions. Proc Natl Acad Sci USA 106:9322-9327

Körner C, Jetz W, Paulsen J, Payne D, Rudmann-Maurer K, Spehn EM (2016) A global inventory of mountains for bio-geographical applications. Alp Bot 127:1-15

Kosaka Y, Saikia B, Mingki T, Tag H, Riba T, Ando K (2010) Roadside distribution patterns of invasive alien plants along an altitudinal gradient in Arunachal Himalaya, India. Mt Res Dev 30:252-258

Levine JM (2000) Species diversity and biological invasions: relating local process to community pattern. Science 288:852-854

Li XH, Zhu XX, Niu Y, Sun H (2014) Phylogenetic clustering and overdispersion for alpine plants along elevational gradient in the Hengduan Mountains Region, southwest China. J Syst Evol 52:280-288
Lososová Z, de Bello F, Chytrý M, Kühn I, Pyšek P, Sádlo J, Winter M, Zelený D (2015) Alien plants invade more phylogenetically clustered community types and cause even stronger clustering. Glob Ecol Biogeogr 24:786-794

Manish K (2019) Macroecological patterns and drivers of Himalayan plant species diversity and distribution through the ages. Front Biogeogr 11:e38754. https://doi.org/10.21425/F5FBG38754

Manish K, Pandit MK (2018) Phylogenetic diversity, structure and diversification patterns of endemic plants along the elevational gradient in the Eastern Himalaya. Plant Ecol Divers 11:501-513

Manish K, Pandit MK (2019) Identifying conservation priorities for plant species in the Himalaya in current and future climates: a case study from Sikkim Himalaya, India. Biol Conserv 233:176-184

Manish K, Pandit MK, Telwala Y, Nautiyal DC, Koh LP, Tiwari S (2017) Elevational plant species richness patterns and their drivers across non-endemics, endemics and growth forms in the Eastern Himalaya. J Plant Res 130:829-844

Manish K, Pandit MK, Sen S (2021) Inferring the factors for origin and diversifications of endemic Himalayan flora using phylogenetic models. Model Earth Syst Environ. https://doi.org/10.1007/s40808-021-01251-z

Marini L, Bertolli A, Bona E, Federici G, Martini F, Prosser F, Bommarco R (2013) Beta-diversity patterns elucidate mechanisms of alien plant invasion in mountains. Glob Ecol Biogeogr 22:450-460

McDougall KL, Khuroo AA, Loope LL, Parks CG, Pauchard A, Reshi ZA, Rushworth I, Kueffer C (2011) Plant invasions in mountains: global lessons for better management. Mt Res Dev 31:380-387

Morlon H, Schwilk DW, Bryant JA, Marquet PA, Rebelo AG, Tauss C, Bohannan BJ, Green JL (2011) Spatial patterns of phylogenetic diversity. Ecol Lett 14:141-149

Morueta-Holme N, Engemann K, Sandoval-Acuña P, Jonas JD, Segnitz RM, Svenning JC (2015) Strong upslope shifts in Chimborazo's vegetation over two centuries since Humboldt. Proc Natl Acad Sci USA 112:12741-12745

Müllerová J, Vítková M, Vitek O (2011) The impacts of road and walking trails upon adjacent vegetation: effects of road building materials on species composition in a nutrient poor environment. Sci Total Environ 409:3839-3849

Naeem S, Knops JM, Tilman D, Howe KM, Kennedy T, Gale S (2000) Plant diversity increases resistance to invasion in the absence of covarying extrinsic factors. Oikos 91:97-108

Pandit MK (2017) Life in the Himalaya: an ecosystem at risk. Harvard University Press, Cambridge (MA)

Pandit MK, Manish K, Koh LP (2014) Dancing on the roof of the world: ecological transformation of the Himalayan landscape. Bioscience 64:980-992

Pathak HN, Bhuju DR, Shrestha BB, Ranjitkar S (2021) Impacts of invasive alien plants on ecosystem services of Ramsar lake cluster in middle mountain Nepal. Glob Ecol Conserv 27:e01597. https://doi.org/10.1016/j.gecco. 2021.e01597

Pauchard A, Kueffer C, Dietz H, Daehler CC, Alexander J, Edwards PJ, Arévalo JR, Cavieres LA, Guisan A, Haider S, Jakobs G (2009) Ain't no mountain high enough: plant invasions reaching new elevations. Front Ecol Environ 7:479-486

Pedersen EJ, Miller DL, Simpson GL, Ross N (2019) Hierarchical generalized additive models in ecology: an introduction with MGCV. PeerJ 7:e6876. https://doi.org/10.7717/peerj.6876

Pimentel D, Zuniga R, Morrison D (2005) Update on the environmental and economic costs associated with alien-invasive species in the United States. Ecol Econ 52:273-288

Pyšek P, Richardson DM, Rejmánek M, Webster GL, Williamson M, Kirschner J (2004) Alien plants in checklists and floras: towards better communication between taxonomists and ecologists. Taxon 53:131-143

Qian H, Field R, Zhang JL, Zhang J, Chen S (2016) Phylogenetic structure and ecological and evolutionary determinants of species richness for angiosperm trees in forest communities in China. J Biogeogr 43:603-615

R Development Core Team (2011) R: a language and environment for statistical computing. Vienna (Austria): R Foundation for Statistical Computing

Raghubanshi AS, Rai LC, Gaur JP, Singh JS (2005) Invasive alien species and biodiversity in India. Curr Sci 88:539-540

Rao CR (1982) Diversity and dissimilarity coefficients: a unified approach. Theor Popul Biol 21:24-43 
Sala OE, Chapin FS, Armesto JJ, Berlow E, Bloomfield J, Dirzo R, Huber-Sanwald E, Huenneke LF, Jackson RB, Kinzig A, Leemans R (2000) Global biodiversity scenarios for the year 2100. Science 287:1770-1774

Seipel T, Kueffer C, Rew LJ, Daehler CC, Pauchard A, Naylor BJ, Alexander JM, Edwards PJ, Parks CG, Arevalo JR, Cavieres LA (2012) Processes at multiple scales affect richness and similarity of non-native plant species in mountains around the world. Glob Ecol Biogeogr 21:236-246

Sekar KC (2012) Invasive alien plants of Indian Himalayan region-diversity and implication. Am J Plant Sci 3:177-184

Sharma G, Rai LK (2012) Climate change and sustainability of agrodiversity in traditional farming of the Sikkim Himalaya. In: Arrawatia ML, Tambe S (eds) Climate change in Sikkim: patterns, impacts, initiatives. Information and Public Relations Department Government of Sikkim, India

Shrestha UB, Gautam S, Bawa KS (2012) Widespread climate change in the Himalaya and associated changes in local ecosystems. PLOS ONE 7:e36741. https://doi.org/10.1371/journal.pone.0036741

Sol D, Maspons J, Vall-Llosera M, Bartomeus I, García-Peña GE, Piñol J, Freckleton RP (2012) Unraveling the life history of successful invaders. Science 337:580-583

Srivastava RC (1998) Flora of Sikkim (Ranunculaceae-Moringaceae). Oriental Enterprises, Dehradun

Stein A, Gerstner K, Kreft H (2014) Environmental heterogeneity as a universal driver of species richness across taxa, biomes and spatial scales. Ecol Lett 17:866-880

Stohlgren TJ, Binkley D, Chong GW, Kalkhan MA, Schell LD, Bull KA, Otsuki Y, Newman G, Bashkin M, Son Y (1999) Exotic plant species invade hot spots of native plant diversity. Ecol Monogr 69:25-46

Tarasi DD, Peet RK (2017) The native-exotic species richness relationship varies with spatial grain of measurement and environmental conditions. Ecology 98:3086-3095
Tecco PA, Pais-Bosch Al, Funes G, Marcora PI, Zeballos SR, Cabido M, Urcelay $C$ (2016) Mountain invasions on the way: are there climatic constraints for the expansion of alien woody species along an elevation gradient in Argentina? J Plant Ecol 9:380-392

Telwala Y, Brook BW, Manish K, Pandit MK (2013) Climate-induced elevational range shifts and increase in plant species richness in a Himalayan biodiversity epicentre. PLoS ONE 8:e57103. https://doi.org/10.1371/journal. pone.0057103

Vetaas OR, Grytnes JA (2002) Distribution of vascular plant species richness and endemic richness along the Himalayan elevation gradient in Nepal. Glob Ecol Biogeogr 11:291-301

Vilà M, Hulme PE (2017) Impact of biological invasions on ecosystem services. Springer, Cham

Webb CO (2000) Exploring the phylogenetic structure of ecological communities: an example for rain forest trees. Am Nat 156:145-155

Webb CO, Ackerly DD, McPeek MA, Donoghue MJ (2002) Phylogenies and community ecology. Annu Rev Ecol Syst 33:475-505

Webb CO, Ackerly DD, Kembel SW (2008) Phylocom: software for the analysis of phylogenetic community structure and trait evolution. Bioinformatics 24:2098-2100

Yang M, Lu Z, Fan Z, Liu X, Hens L, De Wulf R, Ou X (2018) Distribution of nonnative plant species along elevation gradients in a protected area in the eastern Himalayas, China. Alp Bot 128:169-178

\section{Publisher's Note}

Springer Nature remains neutral with regard to jurisdictional claims in published maps and institutional affiliations.

\section{Submit your manuscript to a SpringerOpen ${ }^{\circ}$ journal and benefit from:}

- Convenient online submission

- Rigorous peer review

- Open access: articles freely available online

- High visibility within the field

- Retaining the copyright to your article

Submit your next manuscript at $\boldsymbol{\nabla}$ springeropen.com 